\title{
A ESCUTA DAS IMAGENS
}

Wenceslao Machado de Oliveira Jr. ${ }^{1}$

Ao entrarmos em qualquer sala de aula ingressamos em um ambiente onde reina a oralidade. Ali estabelece-se um universo onde as palavras são responsáveis pela existência das relações entre pessoas, conhecimentos e saberes. São as palavras que dão permanência e continuidade às nossas aulas.

As palavras ditas em classe não têm existência senão em um corpo que as pronuncia diante de inúmeros corpos que as escutam. O reinado da oralidade não se faz somente com voz e ouvido, mas com gestos, tonalidades, olhares, risos... tudo isso compõe uma situação oral, participando dela também aqueles corpos aparentemente passivos às ações humanas, como paredes, roupas, objetos escolares, fotografias, óculos, animais que adentrem a sala de aula...

O corpo que pronuncia as palavras e agencia a situação oral é um corpo-professor. Notase isso com facilidade quando temos a maioria das aulas norteadas por programas e atividades com assunto e ritmos definidos pelo professor. Cabe a ele dizer, falar, expor, apresentar o seu conhecimento diante dos corpos-tornados-ouvidos dos alunos. A esses últimos resta o silêncio e as perguntas ao final, para melhor entender o saber que o professor lhes trouxe nas palavras.

Esses são hábitos de ser professor e com eles entramos em nossas salas de aula. Muitas vezes os sentimos vãos e nos perguntamos: deveriam outros saberes serem chamados a participar das conversas em sala de aula? De que modo estes saberes tão dispersos e diversos poderiam compor as aulas?

Uma resposta possível a essa pergunta é criar maneiras diversas de escutar os alunos e demais corpos que compõem uma situação oral de modo que em suas "falas" cheguem até nossas classes outros saberes permitindo que nossas aulas tornem-se atravessadas por eles.

$\mathrm{Na}$ contemporaneidade, a maior parte desses saberes que vem sendo cotidianamente construídos são formados de e por imagens. Por isso, tomo as imagens como foco nesta busca de inventar "escutas" nas práticas de futuros docentes. Tal foco permite-nos conversar acerca das próprias imagens e linguagens nas quais esses saberes tomam existência, enquanto se conversa sobre os assuntos e raciocínios que elas construíram: forma e conteúdo coconstituindo-se mutuamente.

Partimos da verificação de que as imagens, quando aparecem em classe, colocam em questão esse modo de ser professor citado anteriormente, calcado na oralidade meramente falante. Em grande medida isso se dá porque os alunos "descobrem" coisas sozinhos nas imagens, uma vez que sua leitura-escuta é feita tomando a cultura visual como referência. Em nossa sociedade estamos submetidos a um processo de educação visual ininterrupto que dá sentidos às coisas do mundo por meio de imagens (ALMEIDA, 1994).

A prática educativa aqui relatada foi vivenciada com alunos de licenciaturas diversas e busca atuar nessa educação visual, apontando os sentidos já existentes nas imagens, tensionando-os, criando desassossegos e outras possibilidades de sentidos e usos para as imagens em situações escolares.

Uma vez que as imagens são acionadoras de nossos saberes, podem tornar-se "espaços de escuta" aos conhecimentos existentes nos alunos: o que é visto-lido-ouvido numa imagem não está somente nela, mas também. Tanto nós vemos as imagens como elas nos veem; nossa leitura é tanto delas quanto de nós próprios. Ao falar de uma imagem o aluno fala de si mesmo, revela seu conjunto de experiências com e no mundo.

\footnotetext{
${ }^{1}$ Faculdade de Educação - Universidade Estadual de Campinas.
} 
Nesse sentido, “espaços de escuta” seriam

os espaços, existentes nas aulas, para que os alunos possam trazer os seus conhecimentos e experiências pessoais à discussão, utilizando-os na construção de um novo conhecimento, não mais individual, mas coletivo, produzido pela turma. (MACHADO, 2001, p. 4).

Neste texto selecionei fotografias de coisas e locais indefinidos como um desses "espaço de escuta" escolares.
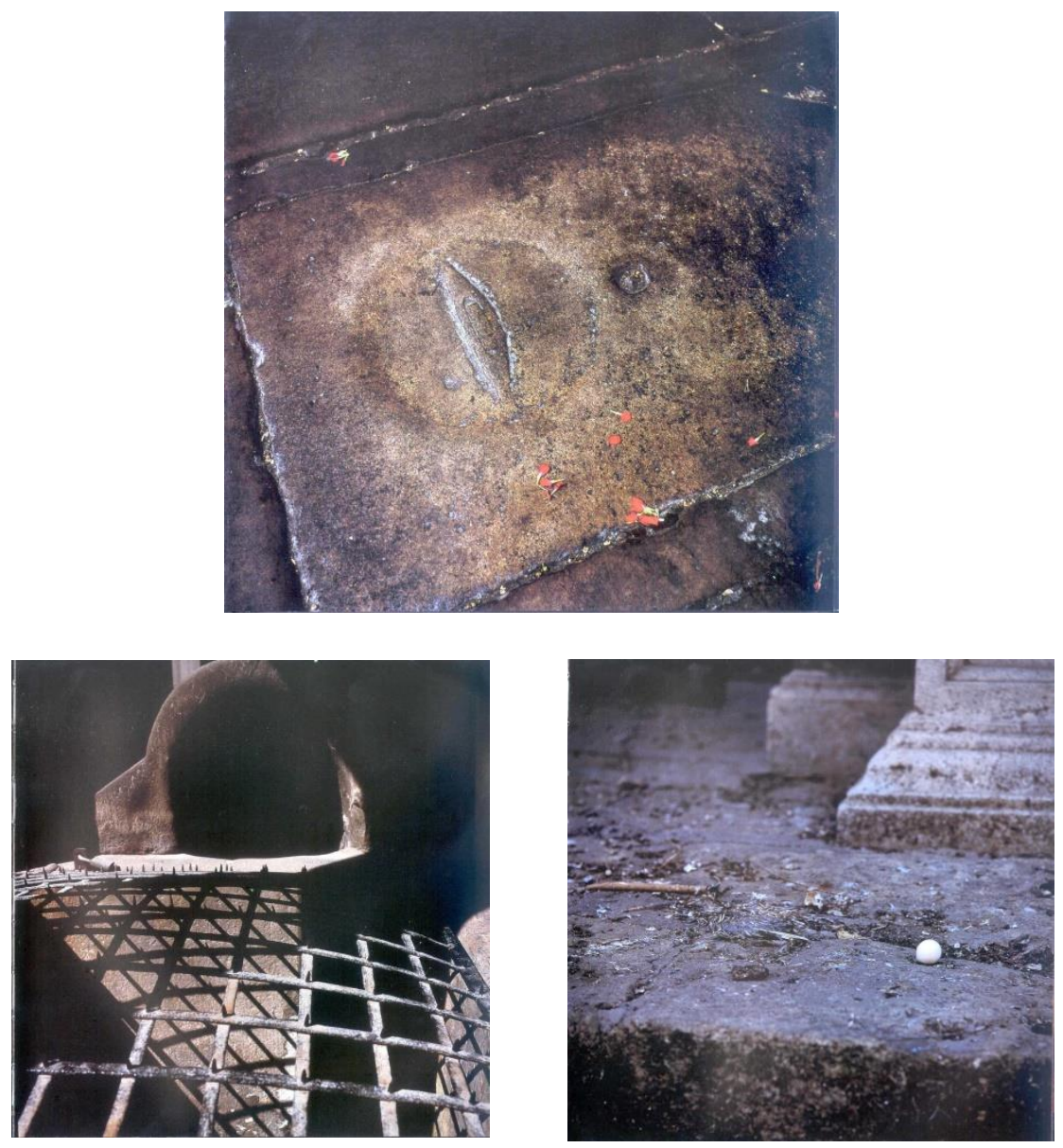

Basicamente esta prática consiste em apresentar fotos como as acima e pedir que digam o que estão vendo. Mostro-as uma de cada vez, demorando o tempo que for necessário em cada uma delas. As três fotos impedem uma leitura fácil e de relance.

Quando ocorre a necessidade de parar para olhar de novo o desafio se estabelece. Não só o desafio de descobrir algum indício que leve à descoberta do mistério, mas o de reconhecer a fotografia como capaz de produzir imagens descoladas da realidade visual cotidiana; fotografias que nos remetem mais a mundos imaginários que a locais existentes.

$\mathrm{Na}$ primeira imagem, os alunos iniciam dizendo ser uma parede ou algo de metal ou concreto de grandes ou médias dimensões. Depois passam a "descobrir" os pontos vermelhoverdes sobre a laje e a relacioná-los a pequenas flores e, então, as dimensões diminuem e passam a ver uma forma que lembra um parafuso ou a forma que remete a um alfinete de cabeça, reduzindo ainda mais as dimensões que atribuem ao objeto-local fotografado.

Mas antes e no entremeio desse processo de redução das dimensões, eles veem nesta imagem bocas, olhos e narizes humanos, além de sombras e personagens de animação e cinema. 
A "fala mobilizadora" do professor tem sido a de perguntar "como você concluiu que isso é uma parede? Que isso é metal? Que isso são flores? Que tem esse tamanho?". Esse é um caminho para promover encontros com o processo de "leitura" das imagens, buscando em nossas memórias visuais as mais diversas formas, brilhos, cores, relações que nos permitam dizer do que estamos vendo.

Tanto na segunda quanto na terceira fotografias continuamos com esse exercício de buscar descobrir o que estamos vendo; não somente na imagem como também em nós mesmos, solicitados que somos pelas imagens que estão diante de nós.

A grade de metal é o que mais comentam e que mais tensiona a segunda imagem, pois ela parece estar solta, despregada e por isso deve estar no chão, pois a gravidade assim o exige, dizem os alunos. Prisões antigas, manicômios e presídios abandonados são os lugares mais citados como sendo o local onde foi tirada a fotografia.

Na terceira imagem a atenção é dividida entre as colunas ao fundo e o ovo/bola de pinguepongue no plano mais próximo. Somente depois são citados restos de aves, penas, madeiras que estão sobre o piso horizontal de pedra.

As "falas mobilizadoras" vêm pedir que pensem onde estariam esses locais fotografados? Quais ambientes teriam essas fisionomias, esses materiais, esses descuidos e cuidados? O que haveria para além das margens da foto? Poderiam ser papeis de parede?

Relatei somente o que se repetiu em diversas turmas, mas muito mais é dito, em "viagens" que vão tornando-se mais e mais divertidas e poéticas quanto mais o desconhecimento vai se fazendo notar, libertando a imaginação da realidade; essa liberação também ocorre quando digo não haver referência alguma no livro de onde estão essas imagens fotográficas: Silent Book.

Nessa escuta das imagens descobre-se que nos amparamos em detalhes para falar do conjunto, que adensamos em torno de partes que mais nos chamaram atenção todo o sentido que nos fica da imagem e do lugar. Descobre-se também que a fotografia dobra a realidade vivida para seu interior. E que, paradoxalmente, talvez seja preciso nos desfazermos dessas experiências com a realidade visual do mundo para que possamos ver algumas fotos, deixarmonos afetar por elas.

Com essa prática busca-se tornar possível experimentar o desassossego diante de fotografias. Ao final é mais tranquilo apontar as fotografias não mais como pedaços da própria realidade a circular impressos em papel e telas, mas obras de uma linguagem com a qual os homens olham e buscam dizer o mundo; uma linguagem com a qual inventam-se mundos, como o fez Miguel Rio Branco.

\section{Referências}

ALMEIDA, M. J. Imagens e sons: a nova cultura oral. São Paulo: Cortez, 1994.

MACHADO FILHO, C. S. Os "espaços de escuta" na formação e atuação do professor. Trabalho de Conclusão de Curso (Bacharelado em Geografia). Universidade Estadual Paulista, Rio Claro, 2001.

RIO BRANCO, M. Silent Book. São Paulo: Cosac Naify, 1997.

\section{Sobre o autor}

Wenceslao Machado de Oliveira Jr. possui graduação em Geografia e Doutorado em Educação. Atualmente é professor no Departamento de Educação, Conhecimento, Linguagem 


\section{A ESCUTA DAS IMAGENS}

e Arte e pesquisador do Laboratório de Estudos Audiovisuais-OLHO, ambos da Faculdade de Educação/Unicamp. Pesquisa na interface entre imagens e educação, bem como em suas conexões com as geografias que dela se desdobram, se descobrem, se criam, se extraem... Atualmente tem focado essas pesquisas nas relações e experimentações entre cinema e escola. E-mail: wences@unicamp.br. 